\title{
A Comparative Study between the Efficacy of Intratympanic Steroid Injection and Conventional Medical Treatment in Resistant Cases of Otitis Media with Effusion
}

https://doi.org/10.47210/bjohns.2021.v29i1.

Rabi Hembrom, ${ }^{1}$ Mukesh Kumar Singh, ${ }^{1}$ Sabyasachi Ghosh, ${ }^{1}$ Sabyasachi Gon, ${ }^{2}$ Indranil Das, ${ }^{1}$ Tapas Kumar Mahata, ${ }^{1}$ Subanta Bhaumik ${ }^{1}$

\section{Introduction}

\section{ABSTRACT}

Otitis media with effusion (OME) is a multifactorial disease and the treatment options for it are limited and controversial. The aim of the present study was to compare the efficacy of intratympanic steroid injection and conventional medical treatment in resistant cases of OME with hearing loss.

Materials and Methods

A comparative study was conducted among 20 patients of OME with hearing loss, resistant to conventional medical treatment between December 2019 to November 2020. 'Intratympanic dexamethasone injection' (ITDI) was given every week for 3 consecutive weeks to one group and the other group continued to receive medical treatment. Hearing was assessed by performing pure tone audiogram before every ITDI and also at 12 weeks follow up after completion of treatment.

$\underline{\text { Results }}$

Hearing improvement was found to be better in the group which received ITDI (Mean AC-PTA hearing gain $=22.88 d B$ ) than the group where conventional medical treatment was continued (Mean $A C-P T A$ hearing gain $=6.83 \mathrm{~dB}$ ).

Conclusion

Intratympanic dexamethasone injection has significantly better outcome in term of improvement of hearing loss in resistant cases of OME than conventional medical management, and is an effective and safe therapy.al.

Kevwords

Otitis Media with Effusion; Injection,Intratympanic; Dexamethasone

$\mathrm{T}$ The Otitis media with effusion (OME) is a multifactorial disease. An acute OME is defined by the presence of middle ear effusion for less than 3 weeks, subacute from 3 weeks to 3 months and chronic for more than 3 months. Pathogenesis of chronic OME is more complex than can be explained by a single cause. It probably represents an interaction between genetic predisposition and triggering factors such as infection and allergy. ${ }^{1,2}$

Pathologically, the disease is characterized by secretory transformation of the epithelium lining the middle ear cavity and subepithelial edema, and infiltration of phagocytes and lymphocytes. The fluid in the middle ear cavity may result from either transudation or exudation

1 - Department of ENT, Midnapore Medical College \& Hospital, Midnapore

2 - Department of ENT \& Head and Neck Surgery,

Vivekananda Institute of Medical Sciences, Kolkata

Corresponding author:

Dr Sabyasachi Gon

email: drsgon@gmail.com 
and active secretion from the epithelial cells. ${ }^{3}$

The prevalence of OME varies widely with age. Though the studies on prevalence of OME in different parts of the world are available, similar studies are limited on Indian population, more so in older age group. Kumari MS et al reported a prevalence of OME $(16.6 \%)$ in a study on south Indian population. ${ }^{4}$

The prevalence of different varieties of OME (acute, subacute, chronic \& resistant) could not be found for Indian / eastern Indian population even with extensive search of the literature.

OME is a leading cause of hearing impairment. Early and proper management of OME prevents its consequences. However, treatment of OME remains a controversial issue. ${ }^{5,6}$

Simple myringotomy and aspiration of effusion do not provide meaningful therapeutic results since their healing duration lasts for only a couple of days. ${ }^{7,8}$ Currently, middle ear aeration through tympanostomy or ventilation tube (VT) insertion is the management of choice for chronic effusion that does not respond to medical therapy. ${ }^{9}$ But, VT insertion may cause adverse effects, such as tube otorrhea, with a reported incidence rate ranging from 29 to $64 \% .^{10,11,12}$

Systemic steroids are known to improve hearing levels in sudden sensorineural hearing loss (SSNHL), Meniere's disease and other inner ear diseases. Intratympanic (IT) steroid injection has the potential to achieve higher steroid concentrations in the inner ear while avoiding the systemic side effects. ${ }^{13}$

Cutler et al \& Roland et al opined that direct application of steroid into middle ear mucosa through tympanostomy tube or intratympanic injections of dexamethasone (ITD) were also found more effective in the reduction of granulation tissue than antibiotic therapy alone. ${ }^{14,15}$

The aim of the present study was to compare the efficacy of intratympanic steroid injection and conventional medical treatment (Antibiotic, intranasal cortico-steroid, oral anti- histaminic, systemic steroid) in resistant cases of OME with hearing loss.

\section{Materials and Methods}

A randomised, prospective, controlled study was conducted in the department of ENT in a tertiary care hospital for a period of one year from December, 2019 to November, 2020. Probability samples by simple random sampling technique has been adopted for the random assignment of the participants to treatment groups in the present study.

The patients aged more than 10 years of age, attending out patient department (OPD) with persistent hearing loss after conventional medical treatment with antibiotics, nasal topical decongestants, intranasal corticosteroid, antihistaminic with or without systemic corticosteroid for a duration of 6 weeks, an otoscopic examination suggestive of OME in one or both ears, pure conductive deafness with normal bone conduction values at $500 \mathrm{~Hz}$, $1 \& 2 \mathrm{KHz}$ and $\mathrm{B} / \mathrm{C}$ type tympanogram, were included in the study.

The patients with mixed hearing loss, familial Mucociliary diseases (like- Kartagener's syndrome), sinonasal pathology (deviated nasal septum, sino-nasal mass etc.), other systemic co-morbidity (hypertension, diabetes mellitus, congestive heart failure etc.) were excluded from the study.

A detailed history of each case was taken, which included chief complaints, history of present illness, history of past illness, family history and personal history and the data was recorded in a proforma. The onset, duration and the progress of the disease symptoms were enquired for, which included deafness, ear blockage or fullness, earache, tinnitus, vertigo and ear discharge, if any. Otoscopic examination of the tympanic membrane and Tuning fork tests were performed in all the cases followed by pure tone audiometry and tympanometry. Anterior and posterior rhinoscopy were done in all the cases to exclude sino-nasal pathology.

The study included 20 patients aged more than 10 years, with resistant OME. They were assigned randomly into 2 groups (10 patients in each group) for the comparative study, after taking written informed consent. In Group A (study group) the patients received intratympanic dexamethasone injection and in Group B (control group) patients continued to receive 
Table I: Distribution of age and sex

\begin{tabular}{|c|c|c|c|c|c|c|c|}
\hline \multirow{2}{*}{\multicolumn{2}{|c|}{ AGE INTERVAL }} & \multicolumn{2}{|c|}{ STUDY GROUP } & \multirow{2}{*}{$\begin{array}{l}\text { STUDY } \\
\text { GROUP } \\
\text { TOTAL }\end{array}$} & \multicolumn{2}{|c|}{ CONTROL GROUP } & \multirow{2}{*}{$\begin{array}{c}\text { CONTROL } \\
\text { GROUP } \\
\text { TOTAL }\end{array}$} \\
\hline & & MALE & FEMALE & & MALE & FEMALE & \\
\hline \multirow{4}{*}{$\begin{array}{c}\text { Age } \\
\text { (in Years) }\end{array}$} & $11-20$ & $\mathbf{0}$ & 1 & 1 & 0 & $\mathbf{0}$ & $\mathbf{0}$ \\
\hline & $21-30$ & 2 & 1 & 3 & 5 & 2 & 7 \\
\hline & $31-40$ & 2 & 3 & 5 & 2 & 1 & 3 \\
\hline & $41-50$ & $\mathbf{0}$ & 1 & 1 & $\mathbf{0}$ & 0 & $\mathbf{0}$ \\
\hline \multicolumn{2}{|c|}{ Total $(n=20)$} & 4 & 6 & 10 & 7 & 3 & 10 \\
\hline
\end{tabular}

conventional medical treatment for another 6 weeks.

Intratympanic steroid injection was given in the outpatient clinic under vision with a binocular microscope. The patient was placed supine and the head turned to the opposite side, the local anaesthesia of the tympanic membrane was achieved with $2 \%$ Inj. Xylocaine. Approximately $0.4-0.6 \mathrm{ml}$ of dexamethasone solution $(4 \mathrm{mg} / \mathrm{ml})$ was loaded into a 1-mL syringe with a long 25-gauge needle attached on it and injected into the tympanic cavity through a hole made in the postero-inferior quadrant of tympanic membrane. The patient was asked to avoid swallowing and remain in the same position for another 10 minutes after injection to allow contact of steroid with the middle ear mucosa. Subsequently, patients received postoperative prophylactic oral antibiotic and if there was no adverse event, were discharged on the same day of the procedure. These injections were repeated once a week for 3 consecutive weeks.

In Group B, patients received conventional medical therapy for 6 weeks, consisting of antibiotic, intranasal corticosteroid, oral antihistaminic, systemic steroid etc.

All the patients were followed up at 1st week (before initiation of therapy) and at $2 \mathrm{nd}, 3 \mathrm{rd} \& 12$ th week by pure tone audiometry. In pure tone audiometry, air conduction pure tone average (AC-PTA) at speech frequencies $(0.5,1 \& 2 \mathrm{KHz})$ were recorded for all the patients at every visit. The hearing gain at 12 th week in comparison to 1 st week were calculated. The results of both the groups were compared and statistically analysed with the help of students unpaired t-test.
Tympanometry were done in both the groups at 1st week \& at 12th week and percentage of change from type B / C to type A / As tympanogram were calculated and compared.

OME resolution (disease-free status) was defined as the disappearance of aural fullness, normal findings on otoscopy, improvement in hearing as less than or equal to $20 \mathrm{~dB}$ AC-PTA and type A tympanogram. Patients were also evaluated for complications such as tympanosclerosis, otorrhea, and persistent TM perforation.

\section{Results}

Total 20 cases of resistant OME with hearing loss were analysed in the present study. All the patients presented with hearing impairment and aural fullness (100\%) as their chief complaints. Tinnitus $(20 \%)$ and intermittent earache $(10 \%)$ were other associated complaints.

The mean age of cases in group A was 31.9 years and 29.1 years in group B, with a range from 15 to 45 years. Among 20 cases, 11 (55\%) were males and remaining 9 $(45 \%)$ were female, with a Male: Female ratio of 1.22:1. (Table I)

On otoscopic examination, no significant abnormality was found in external auditory canal. The tympanic membrane was dull with loss of light reflex and mobility in all the cases. Grade I retraction of the tympanic membrane was seen in $20 \%$ of the ears.

The patients of group A $(n=10$, ears $=17)$ were treated with ITDI and group $B(n=10$, ears $=15)$ patients 
Table II: Ears affected with resistant OME

\begin{tabular}{|c|c|c|c|l|}
\hline \multirow{2}{*}{ GROUP } & \multicolumn{3}{|c|}{ AFFECTED EAR } & \multicolumn{2}{|c|}{ TOTAL NO OF } \\
& LEFT & RIGHT & BILATERAL & EARS \\
\hline Group - A $(\mathbf{n}=\mathbf{1 0})$ & 1 & 2 & 7 & 17 \\
\hline Group - B $(\mathbf{n}=10)$ & 3 & 2 & 5 & 15 \\
\hline
\end{tabular}

continued receiving conventional medical treatment. (Table II)

All the cases were observed for 3 months in this study. There were no signs of perforation, persistent otorrhea or other complications in any of the patients.

Results were evaluated with pure tone audiometry in $1 \mathrm{st}, 2 \mathrm{nd}$, 3rd week and at the end of follow up period (12th week) after the treatment. 15 ears (46.88\%) presented with moderate conductive loss i.e. with 30$45 \mathrm{~dB}$ of Air Bone Gap at speech frequencies. Severe conductive loss was present in 13 ears $(40.63 \%)$ and mild in 4 ears $(12.5 \%)$.

The mean air conduction pure tone average (AC-PTA) at speech frequencies improved at 12 th week by 22.88 $\mathrm{dB}$ in group $\mathrm{A}$ and by $6.83 \mathrm{~dB}$ in group $\mathrm{B}$ in comparison to 1 st week. The hearing gain in the study group (Group A) were found to be extremely statistically significant in comparison to the control group (Group B). (Table III)

Tympanometry was done in all patients at 1 st week and at 12 th week to compare middle ear compliance, middle ear pressure and the curves. All the patients had either type B / C curve at the initiation of therapy i.e. at 1 st week. Among 17 ears $(n=10)$ of group A, type B / C curve changed to type A / As curve in 13 ears (76.47 $\%)$. Whereas in group $B(n=10)$, only 7 out of 15 ears
(46.67\%) were found to have changed from type B / C to type A / As curve. (Table IV)

\section{Discussion}

Otitis media (OM) is the commonest childhood disease after viral upper respiratory infections (VURI). Unlike Acute Otitis Media (AOM), it does not exhibit acute infection symptoms, and it is the inflammatory response of the middle ear that is defined by effusion in the tympanic cavity. ${ }^{2}$

Han et al. have claimed that an intratympanic injection of dexamethasone can be used as a line of treatment in OME. In their study on 84 patients with OME of no more than 2 months duration, it was reported that both oral administration and an intratympanic injection of glucocorticoid are effective for the treatment of OME. ${ }^{16}$

Paksoy et al. carried out a study on 64 patients of OME, who had been treated previously either by medical or by surgical therapy without resolution. Half of their patients had received another course of medical treatment as a control group and the other half was administered $0.5 \mathrm{ml}$ dexamethasone once weekly for 4 weeks. They noticed more improvement in patients in the study group than the control group. ${ }^{17}$

Table III: Mean AC-PTA at different visits and Hearing gain (in $\mathrm{dB}$ ) at 12th week in comparison to $1 \mathrm{st}$ week.

\begin{tabular}{|c|c|c|c|c|c|c|}
\hline \multirow[b]{2}{*}{ GROUPS } & \multicolumn{4}{|c|}{$\begin{array}{l}\text { MEAN AIR CONDUCTION PURE TONE AVERAGE } \\
\text { (AC-PTA) }\end{array}$} & \multirow{2}{*}{$\begin{array}{c}\text { MEAN AC-PTA } \\
\text { HEARING GAIN } \\
\text { (AT 12TH } \\
\text { W`EEK IN } \\
\text { COMPARISON } \\
\text { TO 1ST WEEK) }\end{array}$} & \multirow[b]{2}{*}{ P VALUE } \\
\hline & $\begin{array}{l}\text { 1ST } \\
\text { WEEK }\end{array}$ & $\begin{array}{l}\text { 2ND } \\
\text { WEEK }\end{array}$ & $\begin{array}{l}\text { 3RD } \\
\text { WEEK }\end{array}$ & $\begin{array}{l}\text { 12TH } \\
\text { WEEK }\end{array}$ & & \\
\hline Group - A & 46.89 & 37.74 & 29.84 & 24.01 & 22.88 & \multirow{2}{*}{$\begin{array}{l}\text { Less than } \\
0.0001\end{array}$} \\
\hline Group - B & 41.07 & 38.54 & 35.99 & 33.73 & 6.83 & \\
\hline
\end{tabular}


Table IV: Comparison of tympanogram before and after intervention at 12 th week

\begin{tabular}{|c|c|c|c|c|c|}
\hline \multirow{3}{*}{ GROUPS } & \multicolumn{4}{|c|}{ TYMPANOGRAM } & \multirow{3}{*}{$\begin{array}{c}\text { CHANGE } \\
\text { FROM TYPE } \\
\text { B / C TO A / As }\end{array}$} \\
\hline & \multicolumn{2}{|c|}{ 1ST WEEK } & \multicolumn{2}{|c|}{ 12TH WEEK } & \\
\hline & $\mathbf{B} / \mathbf{C}$ & A / As & $\mathbf{B} / \mathbf{C}$ & $\mathbf{A} / \mathbf{A s}$ & \\
\hline $\begin{array}{c}\text { Group A } \\
\text { (Number of } \\
\text { Ears) }\end{array}$ & 17 & $\mathbf{0}$ & 4 & 13 & $76.47 \%$ \\
\hline $\begin{array}{c}\text { Group B } \\
\text { (Number of } \\
\text { Ears) }\end{array}$ & 15 & $\mathbf{0}$ & 8 & 7 & $46.67 \%$ \\
\hline
\end{tabular}

Cutler et al. and Florea et al. performed experimental study in an animal model and reported that intratympanic steroid injections reduced lipopolysaccharide, which induces middle ear effusion. They also suggested that their results supported the current use of antiinflammatory ototopical such as corticosteroids, in the treatment of inflammatory middle ear disease, thereby avoiding systemic side effects..$^{14,18}$

Several studies have concluded that intratympanic injection of long acting steroids is more effective than conventional therapy in the reduction of hearing loss and middle ear pressure. ${ }^{15,19}$

A short course of oral prednisolone is not an effective treatment for most children aged 2-8 years with persistent otitis media with effusion, but is well tolerated. ${ }^{20}$

In the present study, the patients who have received intratympanic steroid injection showed significant hearing improvement compared to the control group who have received conventional medical treatment.

\section{Conclusion}

Otitis media with effusion is a multifactorial disease and treatment options for OME are limited in the form of medical treatment, myringotomy with aspiration of fluid and ventilation tube insertion for chronic cases.

We have presented results of intratympanic injection of dexamethasone, which is a safe and effective method for early resolution of resistant cases of otitis media with effusion. Improvement of hearing and tympanogram was found to be better in the group which received ITDI than conventional medical treatment. No complications like tympanic membrane perforation and / or sensory neural hearing loss was seen.

\section{References}

1. Arola M, Ziegler T, Lehtonen O-P, Puhakka H, Ruuskanen O. Rhinovirus in otitis media with effusion. Ann Otol Rhinol Laryngol. 1990; 99 (6 I):451-3

2. Bluestone CD, Gates GA, Klein JO, Lim DJ, Mogi G, Ogra PL et al. Recent advances in otitis media. Panel reports.1.Definitions, terminology, and classification of otitis media. Ann Otol Rhinol Laryngol. 2002; 111:8-18

3. Ovesen T, Borglum JD. Superoxide dismutase in middle ear fluid from children with secretory otitis media. Acta Otolaryngol. 1992; 112:1017-24

4. Kumari MS, Madhavi J, Krishna NB, Meghanadh KR, Jyothy A. Prevalence and associated risk factors of otitis media and its subtypes in South Indian population. Egypt J Ear, Nose, Throat Allied Sci. 2016;17:57-62

5. Yousaf M, Inayatullah, Khan F. Medical versus surgical management of otitis media with effusion in children. J Ayub Med Coll Abbottabad 2012; 24(1):83-5

6. Kuo CL, Wang MC, Chu CH, Shiao AS. New therapeutic strategy for treating otitis media with effusion in post irradiated nasopharyngeal carcinoma patients. J Chin Med Assoc. 2012; 75(7):329-34

7. Prokopakis EP, Lachanas VA, Christodoulou PN, Bizakis JG, Karatzanis AD, Velegrakis GA. Implications of laser assisted tympanostomy in adults. Otol Neurotol. 2005; 26(3):361-3

8. Sedlmaier B, Jivanjee A, Gutzler R, Huscher D, Jovanovic S. Ventilation time of the middle ear in otitis media with effusion (OME) after CO2 laser myringotomy. Laryngoscope 2002; 112(4):661-8

9. Silverstein H, Light JP, Jackson LE, Rosenberg SI, Thompson JH Jr. Direct application of dexamethasone for the treatment of chronic Eustachian tube dysfunction. Ear Nose Throat J 2003; 


\section{$82: 28-32$}

10. Ho WK, Wei WI, Yuen AP, Hui Y,Wong SH. Otorrhea after grommet insertion for middle ear effusion in patients with nasopharyngeal carcinoma. Am J Otolaryngol.1999; 20(1):12-5

11. Hwang CF, Chien CY, Lin HC, Peng JP, Chang HW, Su CY. Laser myringotomy for otitis media with effusion in nasopharyngeal carcinoma patients. Otolaryngol Head Neck Surg. 2005;132(6):924-7

12. Tang NL, Choy AT, John DG, van Hasselt CA. The otological status of patients with nasopharyngeal carcinoma after megavoltage radiotherapy. J Laryngol Otol. 1992;106(12):10558

13. Naganawa S, Satake H, Iwano S, Fukatsu H, Sone M, Nakashima T. Imaging endolymphatic hydrops at 3 tesla using 3D-FLAIR with intratympanic Gd-DTPA administration. Magn Reson Med Sci. 2008;7(2):85-91

14. Cutler JL, Wall M, Labadie RF. Effects of ototopic steroid and NSAIDS in clearing middle ear effusion in an animal model. Otolaryngol Head Neck Surg. 2006; 135(4):585-9

15. Roland PS, Anon JB, Moe RD, Conroy PJ, Wall GM, Dupre $\mathrm{SJ}$ et al. Topical ciprofloxacin/dexamethasone is superior to ciprofloxacin alone in paediatric patients with acute otitis media and otorrhea through tympanostomy tubes. Laryngoscope 2003; 113:2116-22
16. Han Z, Zhibin C, Dengyuan W, Xia X, Xiaonian Z, Guangqian $X$. The therapeutic effects of oral administration and intratympanic injection of glucocorticoid in the treatment of otitis media with effusion. Journal of Audiology and Speech Pathology 2009;17(6):560-2

17. Paksoy M, Altin G, Eken M, Hardal U. Effectiveness of intratympanic dexamethasone in otitis media with effusion resistant to conventional therapy. Indian J Otolaryngol Head Neck Surg. 2013; 65(Suppl 3):461-7 doi:10.1007/s12070-0110281-Z

18. Florea A, Zwart JE, Lee CW, Depew A, Park SK, Inman J et al. Effect of topical dexamethasone versus rimexolone on middle ear inflammation in experimental otitis media with effusion. Acta Otolaryngol. 2006;126(9):910-5. doi: $10.1080 / 00016480600606699$

19. Datema FR, Vemer-van den Hoek JG, Wieringa MH, Mulder PM, Baatenburg de Jong RJ, Blom HM. A visual analog scale can assess the effect of surgical treatment in children with chronic otitis media with effusion. Int J Pediatr Otorhinolryngol. 2008; 72(4):461-7. doi:10.1016/j.ijporl.2007.12.004

20. Francis NA, Cannings- John R, Waldron CA. Oral steroids for resolution of otitis media with effusion in children (OSTRICH); a double blinded, placebo-controlled randomized trial. Lancet 2018; 392:557-68. 